\title{
Universidad Tecnológica de El Salvador. Un caso de valoración patrimonial en el centro histórico de San Salvador
}

\author{
Melissa Regina Campos Solórzano \\ Antropóloga \\ Magister en Patrimonio Cultural y Territorio \\ melissa.campos@utec.edu.sv
}

\section{Resumen}

El Salvador, fue uno de los países cuyo auge surgió luego del proceso de Independencia con la llegada de la época republicana. Las ganancias que produjo el cultivo de café permitieron la construcción de edificaciones elitistas con marcadas influencias de la arquitectura importada de Europa en las inmediaciones de lo que hoy se constituye como el centro histórico de San Salvador. En este contexto territorial, pero resignificado culturalmente inició en 1986 la expansión arquitectónica del campus de la Universidad Tecnológica de El Salvador, la cual al día de hoy conforma un paisaje urbano particular con 21 edificaciones color ocre y crema dispersas en el extremo poniente del centro de la ciudad, así se refleja el compromiso agresivo de la Utec —más allá de su comunidad universitaria- que se extiende a la sociedad a través de la conservación del patrimonio cultural universitario.

Palabras clave: Patrimonio cultural universitario, colecciones, valoración cultural, significación cultural, conservación.

\begin{abstract}
El Salvador was one of the countries whose growth surged after the process of independence and with the arrival of the republican period. The profits that were produced by the coffee cultivation permitted the construction of elite buildings distinguished by architecture imported from Europe in those zones that today constitute the Central Historical District of San Salvador. It was in this area of the city and with a new sense of historical significance that the Universidad Tecnológica de El Salvador (Utec) initiated the architectural expansion of its campus. Today, the area makes for a unique urban landscape with 21 buildings painted in colors of cream and crimson dispersed throughout the extreme western part of the center of the city. The site also reflects the strong commitment Utec
\end{abstract}


has extended - beyond the limits of its commitments as a university - to our society through the conservation of the university's cultural heritage.

Key Words: university cultural heritage, collections, cultural worth, cultural significance, conservation

El presente artículo pretende exponer los intereses conservacionistas de una relativamente joven universidad salvadoreña, la cual, en un contexto de globalización mundial, ha decidido permanecer dentro de los límites del centro histórico de la ciudad capital de San Salvador. Esta reflexión se realiza en el marco del encuentro del Primer Seminario de Patrimonio Cultural Universitario, llevado a cabo en La Habana, Cuba, en marzo de 2015. La presentación se llevará a cabo en cuatro partes, en las que se desarrollarán brevemente los temas relacionados, que dan sentido al título de la ponencia.

La primera parte explorará la evolución histórica del territorio de la ciudad de San Salvador y cómo ha llegado a conformarse en un paisaje urbano particular definido por un singular espíritu de lugar. La segunda parte tiene como eje la historia universitaria de El Salvador, donde en este caso se hace evidente la reciente aparición de la educación superior en el ámbito privado y su consolidación hacia finales del siglo XX. La tercera parte indagará, por un lado, sobre el patrimonio edificado, arquitectónico e inmueble contenido en el campus universitario, y por otro, el contenido cultural mueble almacenado y exhibido en el Museo Universitario de Antropología, MUA.

Por último, se expone una serie de reflexiones relacionadas con las perspectivas de difusión del patrimonio universitario y la puesta en valor de las colecciones como articuladora del trinomio Territorio-Universidad-Patrimonio; $\mathrm{y}$ cómo esto es un desafío aun por abordar.

\section{San Salvador: breve aproximación al desarrollo territorial del centro histórico capitalino}

Fundada en 1546, la ciudad de San Salvador rindió tributo, durante la época colonial, a la Capitanía General de Guatemala (conformada por los actuales territorios de Chiapas, Guatemala, El Salvador, Honduras, Nicaragua y Costa Rica) a través de lo recaudado por los cultivos de añil, bálsamo y cacao, principalmente. El poco excedente del comercio de estos productos sirvió como base para la conformación de las primeras edificaciones en la ciudad. ${ }^{1}$

Luego de casi tres siglos de permanecer bajo la monarquía absolutista, teocrática y feudal de los españoles, se firmó en 1821 la independencia centroamericana del gobierno ibérico. Sin embargo, la secesión dejó un vacío de poder político 1 Edificaciones modestas que sucumbieron ante los frecuentes terremotos o por la idea moderna de progreso. 
institucional y una depresión económica; lo que llevó conformar en 1824 la República Federal de Centro América, esfuerzo que no duraría más de dos décadas debido a varias guerras civiles entre los mismos Estados por el poder, por lo que llegó a su término en 1841, pasando a ser Guatemala, El Salvador, Honduras, Nicaragua y Costa Rica las cinco nuevas repúblicas independientes, libres y soberanas (Herodier, 1997).

Hacia mediados del siglo XIX, el café sustituyó al cultivo de añil como base de la economía nacional; se promulgaron leyes tributarias a favor de una nueva clase dominante de terratenientes y sus cafetales; sus plantaciones se convertirían en el principal producto de agroexportación de la economía salvadoreña; cobró tal importancia, que sería este cultivo el impulsor de las reformas radicales de la tenencia de la tierra. Estas ayudarían a la conformación de una nueva elite social (Herodier, 1997; Erquicia, 2012).

Las ganancias que producía el monocultivo del café eran visibles y, a diferencia de los cultivos coloniales, quedaban en poder del capital nacional; con ello se construyeron edificaciones elitistas con las más marcadas influencias de la arquitectura importada de Inglaterra y Francia en las inmediaciones de lo que hoy se constituye como el centro histórico de San Salvador. Estas nuevas estructuras arquitectónicas impusieron, a finales del siglo XIX, una nueva tendencia para la valoración de lo histórico-artístico propio de las élites, coincidiendo en temporalidad con uno de los terremotos más devastadores ${ }^{2}$ para la ciudad... 1873, la ciudad caería destruida como consecuencia de un fuerte sismo, siendo este evento el que daría la pauta para la reconstrucción de la ciudad con nuevos y vanguardistas sistemas de construcción que dejaron atrás las edificaciones coloniales vulnerables a los temblores.

Los nuevos edificios fueron producto de la voluntad política y la bonanza de las familias comerciantes y productoras de café, que se involucraron en la construcción de las nuevas construcciones de proporciones monumentales, que dieron un aire de esplendor a la ciudad de San Salvador de principios del siglo XX.

Sin embargo, la bonanza duraría menos de lo esperado. Para 1930 cayó el precio del café, como consecuencia de la gran crisis económica mundial, y con ello descendieron el número de nuevas construcciones; la ciudad crecía de manera peculiar: por un lado se ensanchaba de norte a sur con sectores populares y, por otro, se alargaba de oriente a occidente con las residencias de clases altas.

A mediados del siglo XX el inminente abandono del centro de la capital llevó consigo un cambio en los usos del suelo y la consecuente marginación del espacio. El centro de la ciudad, que había tenido un uso habitacional de las élites, cambió su población a clases populares y pasó a ser sede de la actividad comercial y financiera de la capital.

2 San Salvador, por sus condiciones geográficas, se ha caracterizado por sufrir periódicamente sismos de gran magnitud. 
A finales del siglo XX, la década de los setenta fue determinante para el inicio de un período de crisis social y económica que vendría seguido del inicio y posterior agudización de la época violenta que suscitaron los doce años de guerra civil salvadoreña, dada la serie de eventos represivos por parte del Estado y organizaciones paramilitares, replicados por acciones violentas de las organizaciones sindicales que peleaban por la desigualdad de clases y por la represión que existía en ese tiempo contra todo aquel que estuviese en contra del gobierno militar (Romero, 2005).

En 1980 estalló oficialmente el conflicto entre las Fuerzas Armadas salvadoreñas y los grupos guerrilleros, lo que conllevó al incremento masivo del exilio de miles de familias salvadoreñas, principalmente hacia Estados Unidos, en aquella década. Junto con las migraciones, la infraestructura y usos de la ciudad se modificaban. En las calles principales del centro se fueron ubicando ventas informales, que luego de la firma de los Acuerdos de Paz se agudizaron debido a las deportaciones masivas de salvadoreños sin empleo y de miembros de pandillas, que como medio de subsistencia buscaron - entre otras ocupacionesde ser vendedores informales como medio para subsistir.

Desde entonces, ha habido iniciativas de reordenamiento para reubicar a los vendedores y ordenar las calles y aceras, para sus usos peatonales. Sin embargo, han sido procesos ásperos, que han ocasionado como daños colaterales afectaciones al patrimonio edificado de la ciudad.

Actualmente, el centro histórico de San Salvador está conformado 3 por 141 manzanas en total, divididas en tres perímetros claramente delimitados como $A$, o microcentro; $B$, o centro ciudad; $\mathrm{y} C$, o centro consolidado. El área total se encuentra protegida por la Ley Especial de Protección al Patrimonio Cultural (1993), por las ordenanzas municipales y por iniciativas civiles de protección a los monumentos.

\section{Esbozo urbano-arquitectónico de la ciudad de San Salvador}

El tiempo de la Colonia marcó, con la creación de una plaza central y su trazado reticular, la imposición de un nuevo orden urbano en el joven asentamiento de San Salvador en 1528 (Larde y Larín, 2000), haciendo que los espacios público y privado se organizaran bajo los patrones implantados por los españoles; de igual manera, la arquitectura respondió a la imposición de los estilos predominantes en Europa, específicamente el barroco, que se manifestaba de forma tardía en El Salvador debido a los formatos de comunicación de ese entonces y, a la vez, interpretado por la mano de obra indígena, dotándola de un toque particular y de rasgos sencillos.

3 Decreto legislativo n. ${ }^{\circ} 280$, publicado en el Diario Oficial el 21 de agosto de 2008. 
La transición de poder monárquico a un gobierno independiente, en 1821, dio inicio a la era republicana, la cual no generó cambios drásticos en el urbanismo ni en la arquitectura creada en este período, que poco a poco fue abriendo paso al estilo neoclásico que predominaba en Francia; que para entonces se trataba de un foco científico cultural, referente de la época; sin embargo, existió otro factor que definió el paisaje urbano de San Salvador: su sismicidad. El "valle de las hamacas", como se lo conoció en algún momento, fue testigo de fuertes movimientos que causaron el desplome casi completo de la ciudad, por lo que en 1873 tanto el gobierno como la empresa privada generaron las pautas para cambiar el sistema tradicional de construcción del adobe por materiales novedosos y más livianos, como la madera y lámina troquelada. Estilísticamente, las fachadas de la arquitectura en general tenían detalles con reminiscencias afrancesadas, propias del art noveau.

El nuevo siglo trajo consigo nuevos procesos y materiales constructivos que paralelamente existieron, tal es el caso del sistema constructivo francés deployer y el concreto armado. En aquellos ejemplos en que fue aplicado el sistema deployer los estilos arquitectónicos todavía mantenían rasgos academicistas y románticos. Por otra parte, el empleo de los sistemas constructivos de concreto armado trajo consigo el racionalismo y funcionalismo que promulgaba el modernismo y que se extendía a mediados del siglo XX hasta rendirse ante la sencillez del minimalismo bajo la bandera de "menos es más"4.

El Salvador del siglo XXI vive estilísticamente en el período postmodernista, y existen algunos ejemplos que denotan la influencia de este, pero coexiste con un paisaje urbano arquitectónico multiestilístico, pues algunos ejemplos del pasado han resistido a los diferentes embates socioculturales y naturales que han cincelado el perfil de la ciudad. Lastimosamente, de la Colonia solo la traza se mantiene; y de sus edificaciones al parecer no hay ninguna huella física. Los ejemplos arquitectónicos todavía en pie son verdaderos monumentos que, cual faros, intentan establecer un vínculo con el pasado, para mantenerse activos en la memoria de San Salvador.

\section{De la necesidad de la educación superior a la consolidación de la "gran universidad de EI Salvador"}

Hacia finales de la década de los setenta, la explosión del conflicto armado salvadoreño incidió en la salida masiva de población del territorio debido a la ola de violencia en la que los asesinatos, secuestros, bombas y otras situaciones bélicas se presentaban a la orden del día; entre otras consecuencias, dicha inestabilidad social llevó al cierre e intervención militar de la Universidad de El Salvador, UES, en 1981, debido a que se había convertido en un espacio para la ideologización de los estudiantes por parte la guerrilla, por lo cual, en medio de la guerra y la creciente fragmentación social y multiplicidad de visiones 4 Entrevista personal con el Arq. Luis E. Rico, catedrático especialista en historia arquitectónica de la Universidad Tecnológica de El Salvador 
ideológicas, que sumadas a la obligada deserción de la UES, ganaron atención las recién creadas universidades privadas, que se encargaron de atender la demanda académica de la población estudiantil que buscaba obtener un grado superior.

La presión ante la demanda de nuevas universidades se resolvió rápidamente cuando muchos académicos y empresarios nacionales crearon universidades, con la aprobación y promoción gubernamental, con nuevos enfoques, orientaciones y modelos innovadores, tales como las universidades tecnológicas, las humanísticas, las de carácter religioso, las especializadas en el área de salud y las descentralizadas o desconcentradas de San Salvador (Araujo, 2012).

En ese marco de inestabilidad social nació en 1981, por Decreto del Ejecutivo, la Universidad Tecnológica (hoy de El Salvador), Utec, la cual, a pesar de la crisis social que imperaba en el país, no suspendió sus labores académicas como parte del compromiso hacia los estudiantes, que para entonces conformaban la primera población estudiantil de 1.279 alumnos (Urbina, 2008).

\section{El devenir de la expansión estructural: una colección arquitectónica en el centro histórico de la ciudad}

Para 1982, se preveía que la demanda estudiantil de la Utec aumentaría en razón del reciente cierre de la UES; y ante esto se dispuso, en la terraza de un inmueble, de diez aulas (Ibíd.), al cual se le conocía como edificio Chahín, ubicado fueras del actual perímetro del centro histórico, sobre la calle Rubén Darío donde permaneció el campus de la universidad hasta 1986.

El 10 de octubre de 1986, un terremoto grado 7.5 grados en la escala de Richter sorprendió a los capitalinos; y bastó un minuto para que destruyera gran parte de la ciudad, dejando muchos edificios por el suelo, entre ellos, el edificio donde se encontraba ubicada la Utec (Chavarria, La Prensa Gráfica, 2013).

Felizmente, ya existían planes de desarrollo de la universidad en un lugar cercano dentro del centro de San Salvador, debido al aumento en la demanda estudiantil que había tenido la Utec en los años anteriores, por lo que la situación de crisis tras la catástrofe natural fue solo un acelerador de la inminente expansión académica y arquitectónica que ha caracterizado a la institución a partir de esa fecha.

Tras un estudio de inmuebles disponibles en ese entonces, el grupo de fundadores de la universidad decidió que sería la Quinta Gloria $^{5}$ el lugar destinado para erigir el nuevo proyecto de asentamiento del campus universitario; allí se inició con la construcción del edificio Simón Bolívar que, por su ubicación céntrica, brindaba - y sigue brindando - facilidades en los desplazamientos y recorridos de la comunidad universitaria.

5 Inmueble residencial de estilo neoclásico que se sacrificó por la necesidad de realizar el proyecto universitario. 
El edificio Simón Bolivar fue el primer inmueble propiedad de la Utec. Se construyó estratégicamente sobre el eje de la calle Arce del centro histórico, decumanus,${ }^{6}$ de la ciudad, que divide su parte poniente en norte y sur.

Posteriormente, a unos metros del Simón Bolivar, sobre el mismo eje, se construyó otra edificación similar: el edificio Francisco Morazán. Con ambos inmuebles se dio inicio a la primera forma de colección de la universidad, la de su arquitectura, la cual, en su expansión ocupa un $6 \%$ del área poniente del centro histórico de la capital, de San Salvador.

\section{Centro histórico de San Salvador}

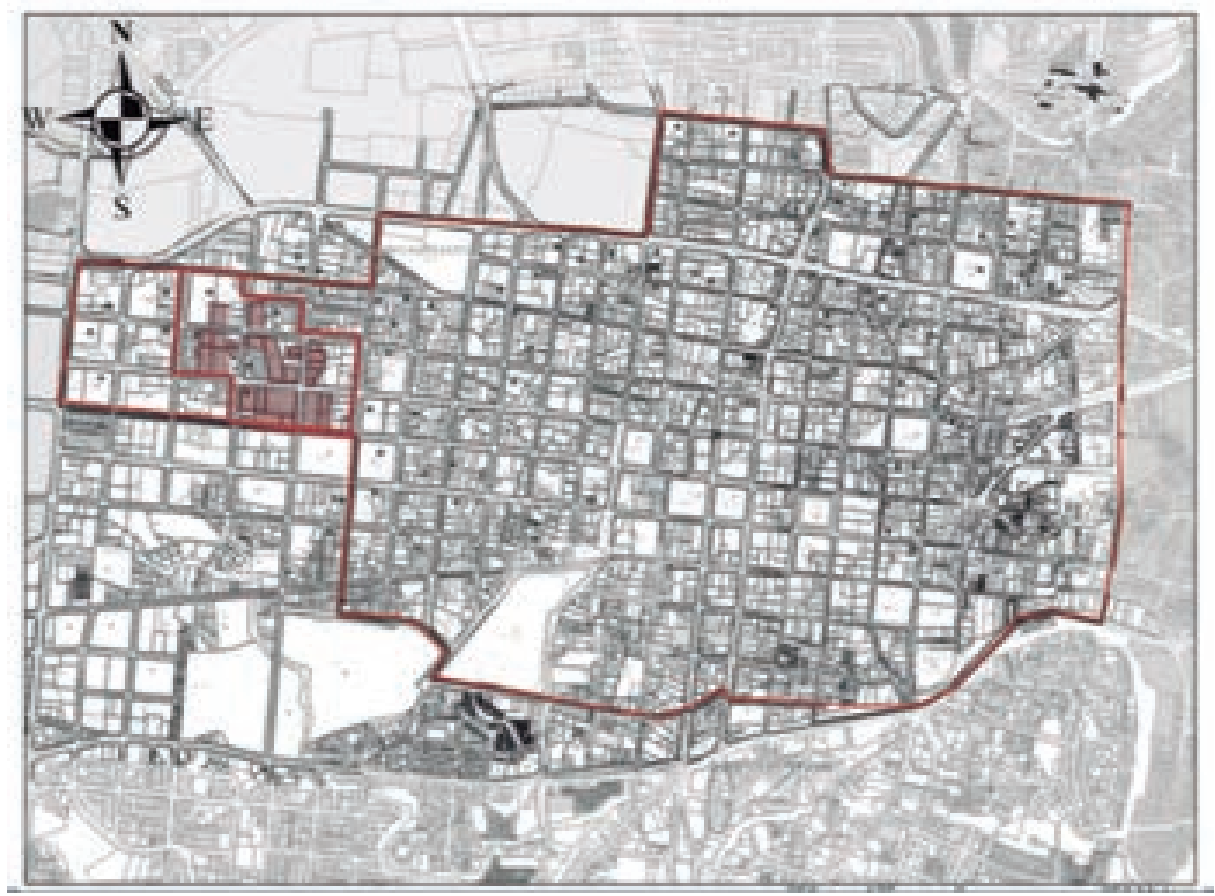

Plano 1. Área que ocupan los edificios y casas de la Universidad Tecnológica de El Salvador al lado poniente del centro histórico de San Salvador. Plano base: OPAMSS, 2013. Elaboración propia.

Ante la creciente demanda de preparación de nuevos estudiantes, y por su céntrica ubicación, la Utec se ha extendido desde entonces en el área de manera dispersa. Por las razones históricas que he mencionado, en el área aún se encuentran residencias que fueron construidas por familias de abolengo salvadoreñas a inicios del siglo XX.

6 Término empleado en la planificación urbanística romana que indica una calle con orientación este-oeste. 
Estas casas, además de estar protegidas por la Ley Especial de Protección al Patrimonio Cultural de El Salvador (1996), han sido valoradas, restauradas y conservadas por decisión de las autoridades universitarias, para devolverles su funcionalidad como áreas para el desarrollo educativo. Por lo anterior, como resultado de la expansión física del campus, producto de la combinación del rescate de inmuebles y la construcción de nuevos edificios, en la actualidad la universidad posee bajo su titularidad 21 inmuebles repartidos en 7 cuadras del centro consolidado de la ciudad.

Vale mencionar que la mayoría de los edificios han sido nombrados, como parte de la visión de los fundadores de la universidad, en honor a personajes que han marcado la historia latino y norteamericana y de la propia historia de la casa de estudios.

\begin{tabular}{|c|c|c|}
\hline $\mathbf{N}^{*}$ & Edificación & Tipo \\
\hline 1 & Simon Bollvar & Edifcio \\
\hline 2. & Francisco Morazin & Edificio \\
\hline 3 & Benito Jutivez & Edficio \\
\hline 4 & Jorge Lisis Borges & Edricio \\
\hline 5 & Federico Garcia Lorca & Edficio \\
\hline 7 & Gabriela Mistral & Edaficio \\
\hline 8 & Joseb Marti & Edilicio \\
\hline 9 & Fundadores & Edifcio \\
\hline 10 & Giuseppe Garibuald & Edifcio \\
\hline 11 & Laboratorio de ingenierla & Casa \\
\hline 12 & Thomas Jefferson & Casa (bien cultural) \\
\hline 13 & Cloudia Lars & Casa (bien cultural) \\
\hline 14 & Ansstasio Aquino & Casa (bien culturai) \\
\hline 15 & Ing Josd Adolfo Araujo Romagaza & Casa (bien cultural) \\
\hline 16 & Casa 116 & Casa (bien cultural) \\
\hline 17 & Casa 118 & Casa (bien cultural) \\
\hline 18 & Casa 125 & Casa (bien cultural) \\
\hline 19 & Casa 130 & Casa (bien cultural) \\
\hline 20 & Casa 131 & Casa (bien cultural) \\
\hline 21 & Casa 135 & Casa (bien cultural) \\
\hline 22 & Casa 135 & Casa (bien cultural) \\
\hline
\end{tabular}

Tabla 1. Colección arquitectónica Utec dentro del centro histórico 

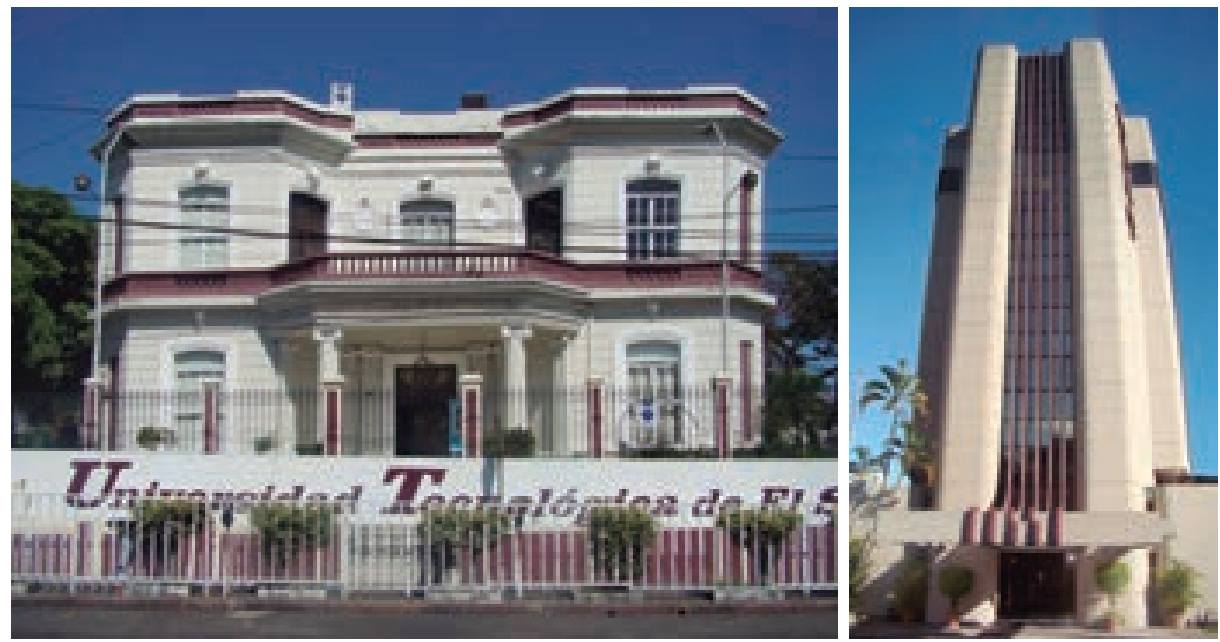

Fotografías 1 y 2: imágenes que muestran la diferencia entre el nuevo edificio de Los Fundadores, y el edificio Anastasio Aquino, casa de principios de siglo XX que actualmente alberga al MUA. Fotos: Rita Araujo.

\section{Un espacio para la cultura}

Paralelamente a la expansión arquitectónica, la Utec ha expandido desde su fundación su oferta académica, abriendo en 1999 las carreras de Antropología, Arqueología e Historia. Por lo que en 2004, al comprarse el moderno edificio de Los Fundadores, ubicado en la $1 .^{\text {a }}$ calle Poniente y 19 av. Norte, se decidió trasladar a dicho edificio la oficina de la Rectoría, que hasta entonces se encontraba en el Anastasio Aquino, de la calle Arce.

Dotadas con valor histórico, arquitectónico, de antigüedad, estético y funcional, ambas edificaciones denotan una dimensión de admiración. El edificio moderno de Los Fundadores, por sus dimensiones y estilizada arquitectura, que se eleva ocho pisos en el plano vertical, pasó a ser sede de las autoridades universitarias, y, en contraparte, se tomó la decisión de convertir el edificio Anastasio Aquino en un museo-escuela, que sería un medio para reforzar las nuevas carreras de Antropología, Arqueología e Historia.?

Para la ejecución del proyecto museológico, en 2005 el señor rector, Dr. José Mauricio Loucel, designó al director de la escuela de Antropología de la Utec de esa época, el connotado antropólogo salvadoreño Dr. Ramón Rivas, la tarea de crear y organizar el nuevo museo en el edificio que había albergado por más de una década las oficinas principales del recinto universitario, la cual, a pesar de todos los usos que tuvo antes de pertenecer a la universidad, no había sufrido ninguna remodelación de fondo en sus espacios originales.

7 La carrera de Historia no se continuo impartiendo. 
Se procedió a adaptar dichos espacios para los propósitos museográficos; y posteriormente se inició con el montaje de las salas, tomando como base una colección de cerámica arqueológica inicial de 312 artefactos, las cuales en su totalidad procedían del período prehispánico mesoamericano de los períodos clásico medio y clásico tardío (250-600 n.e. y 600-900 n.e, respectivamente), pertenecientes a algunas tipologías cerámicas propias del contexto mesoamericano: El Copador, Chalate tallado, Gualpopa, Salúa, Obrajuelo, Negativo Usulután y plomizos, que el señor rector puso a disposición del doctor Rivas.

Para realizar las tareas que llevarían a cumplir con el objetivo, el señor rector delegó en funciones al Lic. Carlos Reynaldo López Nuila, vicepresidente de la Junta General Universitaria de la Utec, para que junto con el doctor Rivas trabajaran en la conformación del primer museo universitario de El Salvador y del centro histórico de San Salvador, y único hasta el día de hoy.

Así, el Dr. Ramón Rivas reunió a un equipo de especialistas en arquitectura, museología, museografía y conservación para trabajar en el proyecto, que se constituyó en poco tiempo en un atractivo especial por su valor agregado al compromiso educativo institucional, como parte de la infraestructura y equipamientos académicos que constituye el campus de la Utec, dignamente posicionado en el entorno histórico patrimonial del centro de la ciudad.

La adaptación museográfica del espacio respetó los pisos, luminarias ornamentales, acabados en madera de cedro, entre otros detalles del estilo arquitectónico original, que son una constante en los espacios internos de las casas antiguas y que, en la actualidad, nos dan una idea sugerente de la cotidianidad de las familias de clase alta de principios de siglo XX.

Habiendo avanzado con el objetivo en una primera fase, el Museo Universitario de Antropología - como fue nominado-, abrió sus puertas en junio de 2006, con tres salas de exposición permanentes, ${ }^{8}$ una temporal y una que sirve de auditorio, para difusión científica-académica.

Las salas correspondían, en la primera planta, a un área con colección arqueológica, entre cerámica y lítica, que narra dos momentos: el primero, la conceptualización del museo bajo referentes de la antropología clásica, arqueología mesoamericana y sitios de interés arqueológico en la zona y el segundo, que muestra la manufactura y comercialización de la cerámica prehispánica en el área mesoamericana.

La segunda sala permanente corresponde a la colección etnográfica, en la que se muestra parte del material recogido durante investigaciones de campo a lo largo del territorio salvadoreño; y otra parte de artefactos y trajes tradicionales de El Salvador.

8 Dos en la primera planta y una en la segunda. 
Posteriormente, en 2008, con la ayuda de fondos de la Cooperación Técnica Japonesa, se inauguró la segunda fase del museo, la que se instaló en la parte poniente de la segunda planta, consistente en una sala dedicada a la discusión del fenómeno de las migraciones, en la que se relata cómo lo han sufrido los grupos humanos desde épocas prehispánicas, sus motivos sociales y naturales y sus consecuencias, siguiendo con el contacto entre los nativos y españoles durante la Conquista y cómo ello influenció en la adaptación de nuevas formas culturales de comportamiento. Luego se abordan las migraciones de salvadoreños en búsqueda de trabajo para recibir el pago en divisas a principios del siglo XX; y por último, la búsqueda del llamado "sueño americano", como el más frecuente fenómeno social de migración de salvadoreños hacia Estados Unidos de América en la actualidad.

Adicionalmente, se adaptó una pequeña sala en la segunda planta dedicada al oficio agropecuario, en la que se contrastan piezas prehispánicas de labranza con los modernos instrumentos para la siembra, que cada vez son menos usados debido a la mecanización de la agricultura.

Por último, en 2014 se instaló una sala dedicada a la los referentes históricos y de la cultura política del país. En ella se narra principalmente el desarrollo biográfico del Ing. Napoleón Duarte, expresidente de la República a quien se le atribuye el mérito de iniciar el proceso democrático en El Salvador por iniciar los diálogos con la guerrilla como antecedentes de los procesos de paz a principios de los años ochenta.

Actualmente, se encuentra en proceso de remodelación la sala permanente de Pancho Lara, que recibe su nombre en honor al cantautor salvadoreño Francisco Lara (1900-1989), cuya colección personal fue cedida a la universidad, para que se exhibiera en el museo desde su primera fase en 2006.

Adicionalmente a las salas permanentes, en el área de la primera planta se encuentran una sala temporal, que presenta exposiciones cuatro veces al año bajo temáticas relacionadas con los contenidos académicos no solo relacionados a la antropología, sino de todas las carreras que ofrece la universidad, cada una acompañada con la producción de un catálogo coleccionable; y además, un auditorio con capacidad para 50 personas, habilitado para el diálogo científico tan necesario en nuestros días y en el que se realizan actos protocolarios y académicos 


\section{Reflexiones que presentan desafíos desafios que se deben superar}

Sin lugar a dudas, la Utec hace parte del paisaje urbano del centro histórico capitalino, que por su compromiso con la sociedad y su liderazgo institucional ha sabido adaptar las necesidades de un campus en crecimiento en coexistencia con edificaciones del siglo pasado de valor cultural patrimonial.

En una época en la que la idea de progreso se ostenta en los tamaños y equipamientos de las edificaciones modernas, la Utec ha decidido mantenerse en un contexto territorial, en la que la adquisición de inmuebles supone una fuerte inversión por sus consecuentes procesos de restauración y reforzamiento de las edificaciones antiguas que les devuelve su valor funcional.

Por otro lado, en la actualidad el MUA se constituye como un espacio de difusión cultural, que promueve los valores científicos y culturales dentro de la comunidad estudiantil. El potencial que brinda su ubicación estratégica en uno de los ejes urbanos más significativos, por su trayectoria histórica en la ciudad de San Salvador debería aprovecharse para el enriquecimiento de sectores más allá de los académicos, en los que se involucre a las comunidades que habitan y recorren la zona del centro histórico, para evolucionar a un modelo dinámico que se articule con las actividades que empujan los constantes cambios sociales.

Nos enfrentamos día a día al desinterés común de la población hacia los museos pasivos, por lo que debemos reflexionar sobre nuevas maneras de mostrar el patrimonio cultural, que da significado y valor a las colecciones universitarias, para poder pensar en discursos renovados que logren acercarnos de manera real a la comunidad y a sus dinámicas en constante transformación.

\section{Referentes bibliográficos}

Araujo, José Adolfo. "Situación de la educación superior en El Salvador desde el enfoque de los marcos regulatorios". Recurso virtual consultado en: http://www.latindex.ucr.ac.cr/ reflexiones-87-2/rfx87-2-12-pdf. Consultado en marzo, 2012.

Chavarria, Ricardo. "A 27 años de la "hecatombe" del 10 de octubre". La Prensa Gráfica. San Salvador, 2013.

Diario Oficial. Decreto legislativo n. ${ }^{\circ}$ 280. San Salvador, 2008.

Erquicia, Heriberto. "El papel de la arqueología en la construcción del Estado-Nación salvadoreño 1883-1930". "Bicentenario", edición conmemorativa. La Prensa Gráfica. San Salvador, 2012.

Erquicia, Heriberto. "La compleja construcción de la 'identidad salvadoreña' 1821-1823". "Bicentenario", edición conmemorativa. La Prensa Gráfica. San Salvador, 2012.

Herodier, Gustavo. San Salvador, el esplendor de una ciudad 1880-1830, Asesuiza, San Salvador, 1997. 
Lardé y Larín, Jorge. El Salvador, historia de sus pueblos, villas y ciudades. Dirección de Publicaciones e Impresos, San Salvador, 2000.

Romero, Ariel. El Salvador, testimonios de guerra, Ed. Gandhy. Maryland, 2005.

Urbina,Chester. "La universidad Tecnológica de El Salvador (1981-2003). Una semblanza histórica". En: Revista Reflexiones n. 87 (2), Ed. Tecnoimpresos, San Salvador, 2008. 


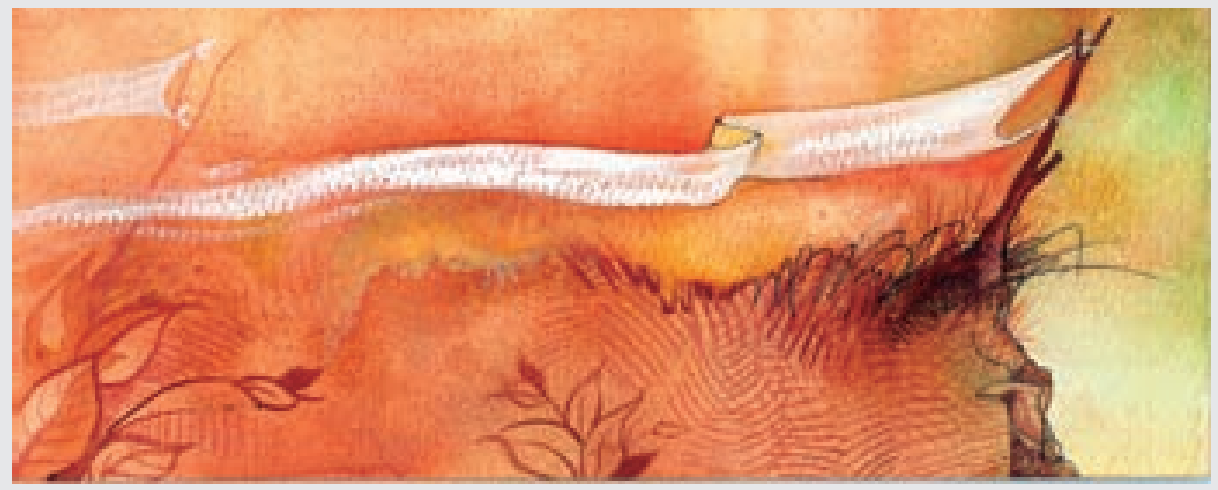

